\title{
Review Article \\ From Placenta to Polycystic Ovarian Syndrome: The Role of Adipokines
}

\author{
Chiara Sartori, ${ }^{1}$ Pietro Lazzeroni, ${ }^{2}$ Silvia Merli, ${ }^{2}$ Viviana Dora Patianna, \\ Francesca Viaroli, ${ }^{2}$ Francesca Cirillo, ${ }^{1}$ Sergio Amarri, ${ }^{1}$ and Maria Elisabeth Street ${ }^{1}$ \\ ${ }^{1}$ Department of Paediatrics, Arcispedale Santa Maria Nuova-IRCCS, Reggio Emilia, Italy \\ ${ }^{2}$ Department of Paediatrics, University Hospital of Parma, Parma, Italy \\ Correspondence should be addressed to Maria Elisabeth Street; mariaelisabeth.street@asmn.re.it
}

Received 2 June 2016; Accepted 1 September 2016

Academic Editor: Mirella Giovarelli

Copyright (C) 2016 Chiara Sartori et al. This is an open access article distributed under the Creative Commons Attribution License, which permits unrestricted use, distribution, and reproduction in any medium, provided the original work is properly cited.

\begin{abstract}
Adipokines are cytokines produced mainly by adipose tissue, besides many other tissues such as placenta, ovaries, peripheral-blood mononuclear cells, liver, muscle, kidney, heart, and bone marrow. Adipokines play a significant role in the metabolic syndrome and in cardiovascular diseases, have implications in regulating insulin sensitivity and inflammation, and have significant effects on growth and reproductive function. The objective of this review was to analyze the functions known today of adiponectin, leptin, resistin, and visfatin from placenta throughout childhood and adolescence. It is well known now that their serum concentrations during pregnancy and lactation have long-term effects beyond the fetus and newborn. With regard to puberty, adipokines are involved in the regulation of the relationship between nutritional status and normal physiology or disorders of puberty and altered gonadal function, as, for example, premature pubarche and polycystic ovarian syndrome (PCOS). Cytokines are involved in the maturation of oocytes and in the regular progression of puberty and pregnancy.
\end{abstract}

\section{Introduction}

Adipokines are produced mainly by adipose tissue, a dynamic endocrine organ involved in the regulation of various endocrine processes such as glucose and fatty-acid metabolism, energy expenditure, inflammatory response, cardiovascular function, and reproduction $[1,2]$. In recent years, adipokines have been found to be produced by other organs also, that is, placenta, ovaries, peripheral-blood mononuclear cells, liver, muscle, kidney, heart, and bone marrow [3, 4], and have been related mainly to insulin sensitivity, inflammation, and other functions [5-7].

Insulin sensitivity and inflammation have been shown to influence both growth [8-10] and ovarian function; in particular there is wide evidence that polycystic ovarian syndrome (PCOS) originates from insulin resistance [11-14] and from excessive exposure to insulin. Excessive exposure to insulin is related to overgrowth and skin lesions, such as acanthosis nigricans, and changes in adipokines, including reduced adiponectin and leptin levels $[1,3]$.
Interestingly, certain conditions such as being born small for gestational age are associated with an increased risk of insulin resistance, metabolic syndrome, and poor growth [15, 16]. Since Barker's theory on the fetal origin of adult disease, it has become clear that the programming of endocrine and metabolic systems is set in utero.

In this review we shall focus mainly on adiponectin, leptin, resistin, and visfatin whose functions are to date better studied compared to other adipokines, considering findings in placenta and newborns, and further described knowledge related to childhood and adolescence.

\section{Description of the Adipokines under Examination}

2.1. Adiponectin. Adiponectin is a $30 \mathrm{kDa}$ secretory protein, which is produced mainly by adipocytes, but also by the placenta, osteoblasts, and cardiomyocytes [8, 17-20].

It is expressed as a full-length protein or as a smaller and globular fragment; this latter form is generated by proteolytic 
cleavage by leukocyte elastase secreted by activated monocytes and neutrophils. Adiponectin circulates as multimers of high, middle, and low molecular weight.

The low-molecular-weight isoforms and trimeric isoforms seem to have effects on the central nervous system [21].

Adiponectin receptors (AdipoR1 and AdipoR2) are integral membrane proteins that are ubiquitously expressed, mediating adiponectin's function at both the central and peripheral levels.

The action mediated by AdipoR1 is for globular adiponectin, while AdipoR2 is a receptor for full-length adiponectin. In cultured cells, such as myocytes and hepatocytes, these receptors increase AMP kinase (AMPK) activities, peroxisome proliferator-activated receptor alpha (PPAR-alfa) activities, fatty-acid oxidation, and glucose uptake $[22,23]$.

Suppression of AdipoR1 reduces fatty-acid oxidation, which is mediated by globular adiponectin. Suppression of AdipoR2 increases fatty-acid oxidation which is mediated by full-length adiponectin. Recent studies show that knockout AdipoRs mice exhibit insulin resistance [24].

In addition, AdipoRs are also decreased in obesity; several authors have demonstrated that expression of both AdipoR1 and AdipoR2 are significantly decreased in muscle and adipose tissue of insulin-resistant mice [25].

These data suggest that adiponectin receptors AdipoR1 and R2 play important roles also in the regulation of insulin sensitivity and glucose metabolism [26].

The main action of adiponectin consists in an upregulation of insulin and energy balance [27]. Functional and genetic studies on adiponectin strongly suggest that reduction in adiponectin levels plays a causal role in the development of insulin resistance (IR), metabolic syndrome, type 2 diabetes, and atherosclerosis. Plasma adiponectin levels are decreased in obesity. In the skeletal muscle, adipokines increase expression of fatty-acid transport and, by activation of peroxisome proliferator-activated receptors (PPARs), increase fatty-acid combustion and energy consumption [28]. Moreover, adiponectin enhances insulin secretion to inhibit gluconeogenesis in hepatocytes [29]. Reductions in plasma adiponectin levels are commonly observed in a variety of states frequently associated with insulin resistance and metabolic syndrome as shown by von Frankenberg et al. who demonstrated that adiponectin levels decrease by increasing the number of metabolic syndrome criteria [5].

Obesity is well known to be characterized by a state of low grade chronic inflammation. Interestingly, adiponectin has been shown to have an anti-inflammatory action and is reduced in obesity. Adiponectin primarily acts modulating macrophage function suppressing TNF-alpha secretion by inhibiting TNF-alpha transcription [30]. This inhibitory action plays an important role on NF-kb activation mediated by TNF-alpha $[30,31]$. Adiponectin stimulates also IL-10 and IL-1 receptor antagonist (RA) production. It is well known that IL-10 has an anti-inflammatory action and can inhibit production of many proinflammatory cytokines [32, 33]. Summarizing, low adiponectin in obesity may contribute to explaining inflammation in these patients.
2.2. Leptin. Leptin is the 167-amino acid product of the human leptin gene (ob gene). It is primarily secreted by the white adipose tissue but is also produced by placenta [34]. Leptin secretion is pulsatile and has significant diurnal variations with higher levels in the evening and early morning and shows relationships with other hormones having a circadian rhythm such as cortisol. The relationship between these two hormones is explained by the direct stimulatory action that leptin has on CRH [35].

Leptin effects are mediated by binding to specific leptin receptors, expressed in the brain and in peripheral tissues such as muscle, liver, adipose tissue, and so forth. There are several isoforms of leptin receptors (ObRs), the most important are ObRa and ObRb [36].

Different functions of leptin have been described, including mediation of food intake, liver glucose production, gonadotropin secretion, suppression of lipogenesis in adipose tissue, and modulation of immune response [37, 38]. Circulating levels of leptin are related to adipose mass. Leptin levels decrease consistently during starvation: low leptin levels induce complex mechanisms in order to preserve energy, that is, increase in appetite, decrease in thermogenesis, decrease in locomotor activity, inhibiting the hypothalamus-pituitarythyroid axis, activating the adrenal axis, and inhibiting reproductive function [37]. Leptin levels are related to timing of $\mathrm{GnRH}$ and $\mathrm{LH}$ secretion as shown in some studies that speculate that reduced pulsatility of LH during the night may be related to low leptin levels present during these hours $[39,40]$.

The absence of leptin or mutations in its receptor induce obesity and hyperphagia. Leptin deficient humans are obese, diabetic, and infertile [41]. This adipokine may therefore play a critical role in regulating both energy homeostasis and the reproductive system, acting as a signal of energy reserve essential for normal reproductive function.

2.3. Resistin. Resistin is a $12.5 \mathrm{kDa}$ peptide, whose name derives from its ability to resist insulin action. In humans, this adipokine is mainly secreted by peripheral-blood mononuclear cells. There are two different forms of resistin: lowand high-molecular-weight isoforms [8, 42]. Resistin acts through interaction with Toll-like receptor (TLR) 4 in human myeloid and epithelial cells. TLR activation initiates a cascade of intracellular events leading to alterations in several transcriptional and signaling pathways, including NF-kb signaling, and thus is tightly connected with inflammatory responses [43].

Resistin was first described as a factor contributing to the development of insulin resistance and diabetes mellitus in humans; a debate is still ongoing regarding its exact role in obesity, in insulin sensitivity, and in the development of type 2 diabetes mellitus (DM2) [44]. Resistin may represent a link between inflammatory processes and metabolic signals. Circulating levels of resistin are increased in obesity. Many authors indicate a solid association between this adipokine and insulin resistance $[45,46]$. Some data suggest that resistin has a role in inflammatory processes, and resistin seems to directly cause endothelial dysfunction [47]. Resistin 
TABLE 1: Site of production and relationship of adipokines with inflammation and metabolic and reproductive function.

\begin{tabular}{|c|c|c|c|c|}
\hline Adipokine & Site of production & $\begin{array}{l}\text { Relationship with } \\
\text { inflammation }\end{array}$ & $\begin{array}{l}\text { Relationship with } \\
\text { metabolic functions }\end{array}$ & $\begin{array}{l}\text { Relationship with } \\
\text { reproductive } \\
\text { function }\end{array}$ \\
\hline Adiponectin & $\begin{array}{c}\text { Adipocytes } \\
\text { Placenta } \\
\text { Osteoblasts } \\
\text { Cardiomyocytes } \\
\end{array}$ & $\begin{array}{l}\text { Anti-inflammatory } \\
\text { functions [30-33] }\end{array}$ & $\begin{array}{c}\text { Fatty acid oxidation [22] } \\
\text { Insulin sensitivity [24] } \\
\text { Glucose metabolism } \\
{[24-29]}\end{array}$ & $\begin{array}{c}\text { Pubertal onset and } \\
\text { regulation } \\
{[104,105]}\end{array}$ \\
\hline Leptin & $\begin{array}{l}\text { Adipose tissue } \\
\text { Placenta }\end{array}$ & $\begin{array}{c}\text { Regulation of } \\
\text { immune response } \\
{[34]}\end{array}$ & $\begin{array}{c}\text { Regulation of food } \\
\text { intake, lipid and glucose } \\
\text { metabolism }[37,38]\end{array}$ & $\begin{array}{c}\text { Regulation of } \\
\text { gonadotropin } \\
\text { secretion [39-41] }\end{array}$ \\
\hline Resistin & $\begin{array}{l}\text { Peripheral-blood } \\
\text { mononuclear cells } \\
\text { Placenta }\end{array}$ & $\begin{array}{l}\text { Regulation of } \\
\text { inflammatory } \\
\text { response }[43,48,50]\end{array}$ & $\begin{array}{c}\text { Insulin resistance } \\
{[44-46]}\end{array}$ & $\begin{array}{l}\text { Ovarian function } \\
\text { and PCOS [55] }\end{array}$ \\
\hline Visfatin & $\begin{array}{c}\text { Adipose tissue } \\
\text { Liver } \\
\text { Muscle } \\
\text { Kidney } \\
\text { Heart } \\
\text { Bone marrow } \\
\text { Placenta }\end{array}$ & $\begin{array}{l}\text { Regulation of } \\
\text { inflammatory } \\
\text { responses [51] }\end{array}$ & $\begin{array}{c}\text { Insulin resistance } \\
\text { Glucose metabolism [52] }\end{array}$ & $\begin{array}{l}\text { Ovarian function } \\
\text { and PCOS [55] }\end{array}$ \\
\hline
\end{tabular}

stimulates secretion of proinflammatory cytokines such as TNF-alpha and IL-6 by macrophages through the NF-kb pathway [48].

In mouse and human models, resistin levels increase in severe inflammatory diseases. An increase in resistin levels has been described in patients having nonalcoholic fatty liver disease (NAFLD) [49], and resistin serum levels have been reported to correlate with hepatic inflammation and necrosis [50].

2.4. Visfatin. Visfatin is a 491-amino acid adipokine. It was previously identified as a protein involved in B cell maturation and is identical to pre-B cell colony-enhancing factor (PBEF), described in 1994 as a cytokine produced by lymphocytes, acting on lymphocyte maturation and inflammatory regulation [51]. Visfatin acts both as a paracrine and an autocrine agent and is secreted by adipose tissue, but it seems to be expressed also in liver, muscle, kidney, heart, bone marrow, and trophoblast and fetal membranes [52, 53].

Recently, visfatin was described as a protein with insulinlike functions. In human studies, a positive correlation between visceral adipose tissue and visfatin gene expression was reported, along with a negative correlation between visfatin and subcutaneous fat, suggesting a different regulation of its expression in these different depots. High levels of visfatin were found in visceral and omental adipose tissue. In contrast, subcutaneous adipose tissue expressed low levels of visfatin [54]. Variable results have been obtained regarding the relationship between visfatin and diabetes or insulin resistance with some authors showing increased visfatin levels in type- 2 diabetes and PCOS patients $[55,56]$.

Furthermore, the role of visfatin in ovarian and/or uterine regulation, via insulin sensitivity or through other mechanisms, remains to be demonstrated yet [2].
In Table 1 we summarize the site of production and the relationship of the above-mentioned adipokines with inflammation, metabolic and reproductive functions.

\section{Role of Adipokines in Pregnancy, Placenta, and Fetus}

The above-mentioned cytokines have all been described in the human placenta in recent years and shown to be related somehow to fetal growth and adiposity [57]. In recent years a potential importance of epigenetic changes in some adipokines is arising relative to metabolic programming and might be involved in the regulation of subsequent postnatal growth and puberty [58].

3.1. Adiponectin. Adiponectin is a placental-produced adipokine whose concentrations have been shown to be related to birth weight $[8,59]$.

Adiponectin concentrations in cord blood of at-term neonates are two to three times higher than those reported in adults [60-62]. The mechanisms by which adiponectin levels are regulated in the placental tissue are not yet well defined. In adults, an increase in fat mass is associated with increasing adiponectin levels, whereas weight loss is associated with reduction in adiponectin concentrations. Moreover, fat mass seems to act as a negative feedback for adiponectin secretion; the lack of such negative feedback in newborns could contribute to hyperadiponectinemia.

Several authors showed a positive correlation between cord blood adiponectin concentrations and birth weight, with higher adiponectin levels in adequate for gestational age (AGA) newborns compared to small-for-gestational age (SGA) and intrauterine growth restricted (IUGR) newborns [63-65]. Adiponectin in placental lysates has been described 
to be significantly lower in IUGR compared with AGA newborns and positively correlated with the weight of the placenta, birth weight, and head circumference [8].

In this respect, a study from Mazaki-Tovi et al. [66] evaluated adiponectin and leptin levels in twins with discordant and concordant growth: in the discordant twin group, while there was no significant difference in the median cord blood leptin concentrations between SGA twins and AGA cotwins, adiponectin levels were significantly lower in growth restricted newborns compared with the concentrations observed in the concordant twins which were similar.

Adiponectin acts as an insulin sensitizing hormone reducing hepatic glucose production and enhancing the insulin-mediated actions of the liver. Low adiponectin levels in low birth weight newborns may therefore predict the subsequent development of visceral fat and insulin resistance.

Moreover, Cianfarani et al. [65] evidenced particularly lower adiponectin levels in SGA children who showed postnatal catch-up growth, compared to those who remained small during late childhood, suggesting a potential role of early catch-up growth for subsequent development of metabolic disturbances.

Regarding large for gestational age (LGA) newborns, another study from Mazaki-Tovi et al. showed that adiponectin placental and cord blood concentrations were lower in macrosomic newborns than in the AGA counterparts [63].

Given that fat mass acts as a negative feedback on adiponectin production and given that hypertrophic adipocytes produce less adiponectin, we can consider the low expression of adiponectin in LGA as a manifestation of these assumptions.

As mentioned above, adiponectin is known to act as an insulin sensitizer. Recent studies showed a positive association between adiponectin and birth length, which may be the expression of the insulin sensitizing action of adiponectin on tissues [64]. Furthermore, Oshima et al. [67] demonstrated an adiponectin-induced activation of osteoblasts, an action that is likely linked to fetal linear growth.

In this context, Ibáñez et al. [68] recently described that IUGR fetuses show a different pattern of adiponectin production, shifted to the high-molecular-weight isoform which is known to be the most closely related isoform to insulin sensitivity. We can assume that this different pattern acts as an insulin sensitizer in the fetus and may promote fetal catch-up growth.

Another aspect of the expression of this adipokine, which suggests a role for adiponectin in fetal growth, is the inverse correlation described between its serum levels and gestational diabetes or obesity [64].

Interestingly, adiponectin gene DNA methylation has been shown to be influenced by maternal hyperglycemia $[58,69]$. Bouchard et al. described lower methylation in the promoter of the adiponectin gene on the fetal side of the placenta in the presence of maternal hyperglycaemia, suggesting that this could contribute to the increased risk of reduced insulin sensitivity, obesity, and diabetes in the offspring in postnatal life [69].
3.2. Leptin. Expression of leptin is widespread in fetal and placental tissues [70] and a relationship between umbilical leptin concentrations and fetal growth indexes, such as birth weight, length and head circumference, and bone mineral density, has been established [71, 72]. Leptin serum concentrations are elevated in the fetus at term, probably acting as a feedback modulator of nutritional conditions and substrate supply [71].

A significant correlation between leptin levels in umbilical cord blood and birth weight of neonates has been described [71, 72]. Infants born small for gestational age (SGA) show lower leptin levels than their appropriate for gestational age (AGA) counterparts [73].

Lea et al. [74] described a relationship between low concentrations of leptin and fetuses born at term with intrauterine growth restriction (IUGR), whereas macrosomic offspring of diabetic mothers showed high leptin serum concentrations. This latter finding was thought to be possibly related to maternal hyperglycaemia that leads to fetal hyperinsulinaemia, which in turn would cause macrosomia via elevated leptin serum levels. In the same study, the placental expression of leptin in a twin pregnancy in which one baby was normal sized while the other showed growth retardation was evaluated: lower levels of leptin were detected in the samples of the growth retarded twin. Tsai et al. [75] and VelaHuerta et al. [76] found significantly higher leptin levels in large for gestational age (LGA) infants than in their AGA counterparts.

Furthermore, leptin has been repeatedly found to be positively related to other factors (i.e., insulin and IGF-I) which are well known to be associated with intrauterine growth.

New insights into the role of leptin in fetal growth have shown cell and tissue specificity, thus leading to speculate that its role in fetal growth may be cell- and tissue-specific [73-75].

Mise et al. [77] investigated the changes in maternal leptin levels in pregnancies complicated by preeclampsia: maternal plasma leptin levels were significantly higher than those of the control group and showed a negative correlation with neonatal body weight. Furthermore, leptin mRNA expression was significantly increased in placenta from women with preeclampsia compared to the control group, showing a similar behaviour as other inflammatory cytokines in that condition. Plasma leptin levels in affected women who delivered SGA newborns were significantly higher than those in women who delivered AGA newborns [78]. Furthermore, the incidence of SGA newborns in women who showed elevated plasma leptin levels was higher than that in women with normal leptin levels. These findings suggested a close correlation between fetal growth restriction and elevated maternal plasma leptin levels [78].

A study comparing pregnancies complicated by gestational diabetes with macrosomic babies and healthy agematched pregnant women and their newborns concluded that gestational diabetes was associated with a downregulation of maternal Th1 cytokines (IL2 and IFN gamma) and an upregulation of leptin and inflammatory cytokines [79]. Furthermore, during pregnancy characterized by impaired glucose tolerance and gestational diabetes, placental DNA 
TABLE 2: Role of adipokines in fetal and postnatal growth and in the onset of gestational metabolic disturbances.

\begin{tabular}{lccc}
\hline Adipokine & $\begin{array}{c}\text { Fetal growth and birth } \\
\text { weight }\end{array}$ & Postnatal catch-up growth & Gestational diabetes \\
\hline Adiponectin & Yes [8,63] & Yes [68] & Yes [64] \\
Leptin & Yes [71-78] & Not described $[79]$ \\
Resistin & Controversial [83, 84] & Not described & Controversial [83, 85, 86] \\
Visfatin & Controversial [87] & Not described & Controversial [88] \\
\hline
\end{tabular}

methylation was reported to be increased on the maternal side of the placenta and to be related to hyperglycaemia. This was associated with leptin gene methylation in placenta and with increased circulating leptin levels in hyperglycaemic pregnant women [80]. These mechanisms could further confirm why newborns exposed to gestational diabetes mellitus have an increased risk of developing obesity and T2DM [58, 81].

3.3. Resistin. Yura et al. [82] and Lappas et al. [83] showed that resistin is expressed in the human placenta. Yura et al. measured resistin expression in maternal adipose tissue, placenta, and fetal membranes and they found out that trophoblastic resistin gene expression was significantly higher in at term placenta than in first trimester placental tissue and that plasma resistin levels in pregnant women were higher than resistin levels in nonpregnant women [82]. High concentrations of resistin in cord blood samples may suggest that this hormone is potentially related to the control of fetal energy expenditure and deposition of adipose tissue.

The expression of resistin in the human placenta is higher than that in adipose tissue. It has been hypothesized that placental resistin may have a physiological meaning in the regulation of maternal glucose metabolism by decreasing insulin sensitivity during human pregnancy. Resistin in placental lysates has been reported to be positively correlated with placental insulin concentration [8].

In the study from Lappas et al. resistin levels were found to be significantly lower in macrosomic fetuses of diabetic mothers compared to control and to be higher in growth restricted pregnancies compared to normal [83]. Maternal and cord blood serum resistin seemed therefore to have a negative correlation with birth weight. Resistin is likely to have an inhibitory effect on adipose conversion, acting as a feedback regulator of adipogenesis. In this respect, as to the fetus, one could assume that low resistin levels in serum are related to excessive production of adipose tissue. This idea could explain the negative correlation described between umbilical resistin concentrations and birth weight.

However, Savino et al. [84], interestingly, found no correlation between breast milk resistin concentrations and maternal anthropometric measurements.

Another study from Vitoratos et al. [85] did not show significant differences in umbilical resistin levels between infants born from women with gestational diabetes (GMD) as compared to normal pregnant women.
In a recent review of the literature [86], according to the data from the 11 studies analyzed, there was no association between circulating resistin levels and gestational diabetes.

So far, we therefore do not have univocal results regarding the role of this adipokine in determining fetal growth and metabolism in normal and abnormal pregnancies.

3.4. Visfatin. Findings concerning visfatin and its possible relationships with fetal growth are controversial and often inconsistent despite recent findings of high concentrations of visfatin in cord blood which leads to assuming a placental production and relationships with fetal growth. Higher visfatin levels have been found in term IUGR newborns compared to their AGA counterparts. This finding may be linked to the different visceral adiposity or altered visceral adiposity in IUGR, which is known to be related to insulin resistance in adulthood [87].

$\mathrm{Hu}$ et al. [88] reported that serum visfatin levels were markedly decreased in women with pre-eclampsia compared with normal pregnant women. These findings suggested a role of visfatin in the determinism of this condition. Moreover, the same study showed no difference in BMI between affected and nonaffected women, suggesting that pathophysiology of pre-eclampsia and visfatin levels are BMI-independent.

In Table 2 we summarize the role of the above-mentioned adipokines in the determinism of fetal and postnatal growth and in the onset of gestational metabolic disturbances such as gestational diabetes.

\section{Role of Adipokines in Puberty}

Birth weight, insulin sensitivity, and adipokines are involved in puberty and its disorders. Puberty is a complex physiological process influenced by different factors, including neuroendocrine circuits and many circulating molecules, some of which still remain unknown. Many authors report a relationship between increasing rates of overweight and obesity in childhood and a trend towards an anticipation of pubertal onset, especially in girls. These observations have generated an increasing interest in pinpointing the mechanisms by which pubertal development and reproductive function are influenced by nutritional status. Pubertal development is physiologically characterized by an increase in adipose mass and changes in adipose tissue distribution. Moreover, several authors reported an increase in serum adipokine concentrations. These biochemical and metabolic 
modifications seem to be closely associated with the status of insulin resistance observed during this period. Adipokines represent an important link between nutritional status and pubertal physiology and several pubertal disorders, such as premature adrenarche, premature pubarche, polycystic ovarian syndrome, and constitutional delay in growth and puberty.

4.1. Puberty in SGA and AGA Newborns. Fetal programming of the endocrine axis related to intrauterine growth and events occurred during pregnancy may also contribute to the timing of puberty and to the future reproductive capacity. Pubertal development disorders influence not only sexual maturity, but also adult height, bone mineral density, and reproductive health [89].

It is well known that many factors such as midparental height, chronic diseases, medications, and pubertal development influence final height. Being born SGA according to either weight or length is a risk factor for growth and development disorders, as it is described that they are at higher risk of presenting a final height below their midparental height, as well as developing cardiovascular disease, obesity, diabetes, and other metabolic disorders [89].

Postnatal growth of SGA children has been analyzed in many studies [90-93].

The mean adult height of individuals born SGA was estimated to be approximately 1 SD lower compared to those born appropriate for gestational age (AGA). Furthermore, adult height is lower in subjects born short for gestational age than in those born light for gestational age $[90,93]$.

Most studies on pubertal development in children have explored the relationship between precocious puberty and pubertal growth in children born SGA. Precocious puberty causes advanced bone maturation, accelerated closing of epiphysis, and may compromise adult height. Precocious pubarche and precocious adrenarche have been shown to be more frequent in subjects with a low birth weight $[94,95]$.

Puberty is associated with a physiological state of insulin resistance, and conditions as premature pubarche have also been related to reduced insulin sensitivity and shown to be more frequent in subjects born SGA $[96,97]$.

Furthermore, girls with previous prenatal growth restriction have been described to have more frequently than the general population idiopathic functional ovarian hyperandrogenism and hyperinsulinism at 18 years of age [95].

Neville and Walker [96], in a retrospective Australian study of 89 children with precocious pubarche, also reported that being born SGA according to weight and/or length was an independent risk factor for precocious pubarche, along with prematurity and being overweight/obese. Moreover, SGA children with precocious pubarche show greater changes in weight SDS than AGA children.

It was suggested that rapid weight gain in childhood might predispose to precocious pubarche in susceptible individuals.

Most authors agree on the existence of a relationship between being born SGA, premature pubarche, and exaggerated precocious adrenarche. The possible causes of this association are thought to be insulin insensitivity, increased central adiposity, increased IGF-I levels between the ages of 2 and 4 years and metabolic, and hormonal patterns that are common in SGA children with excess weight gain in early childhood. High levels of IGF-I and insulin resistance stimulate adrenal androgen secretion and the development of precocious pubarche $[94,95,97]$.

Several studies focused on timing and progression of puberty in children born SGA, but the results are difficult to compare due to variations in the definition of SGA, criteria of inclusion, and follow-up periods.

In a large population study on postnatal growth, $87 \%$ of SGA children showed full catch-up growth and reached puberty at a normal age. SGA children who remained short reached puberty earlier than those who presented catch-up growth $[92,98]$.

Persson et al. studied puberty in children divided according to perinatal risk factors: SGA, large for gestational age, short for gestational age, long for gestational age, born prematurely from a pregnancy complicated by pre-eclampsia, and they also considered a group of children without perinatal risk factors. The onset of puberty was defined according to the age at growth spurt. Interestingly, in boys the mean age at onset of puberty was similar based on the presence or absence of risk factors, whereas in girls the onset of puberty was earlier in those born short or light for gestational age [99].

Interestingly, Lazar et al. reported that both SGA children with short stature and AGA children with idiopathic short stature enter puberty at a normal age, but SGA children show a distinct pubertal growth pattern compared to AGA [15].

There is no general agreement on the existence of differences in age at menarche between SGA and AGA girls. Several longitudinal follow-up studies do not find significant differences in the progression of puberty or age at menarche between girls born SGA and AGA [91, 100] while other studies report an earlier age of menarche in girls with fetal growth restriction compared to girls born of appropriate birth weight $[95,101]$.

Interestingly, one study evaluated the development of premature AGA and full-term SGA children, observing that menarche occurred 6 months earlier in the preterm group and 12 months earlier in the SGA group with respect to fullterm AGA controls. The interval of time between onset of puberty and menarche was similar in all groups [102].

If premature pubarche occurs, then menarche before the age of 12 has been reported to be 3 times more prevalent among girls born SGA compared with girls with normal birth weight $[95,97]$.

\section{Adipokines and Pubertal Development}

5.1. Adiponectin. Many studies have shown, in animal models, that adiponectin concentrations change throughout pubertal maturation [103]. Human data confirm this trend and show differences in the pattern of secretion during puberty between males and females. In healthy lean males, but not in females, adiponectin concentrations significantly decline during pubertal maturation, with lower adiponectin 
levels being observed in adolescent boys compared with girls [104]. The authors of this study further showed a negative correlation between adiponectin concentrations, testosterone, and dehydroepiandrosterone sulfate serum levels; however, pubertal stage was shown to be the strongest independent predictor of adiponectin concentrations, followed by body mass index and testosterone. This model did not seem to fit for female pubertal development. Experimental data have shown for testosterone, but not for estrogens, an inhibitory action on adiponectin secretion from adipocytes, confirming a closer correlation between androgens and adiponectin compared with estrogens [105].

Data like these may well explain the gender differences reported for this adipokine concentrations in adults, with the lowest adiponectin levels being found in males [104].

According to recent studies focused on female reproductive function, although adiponectin concentrations do not seem to change significantly during the menstrual cycle, it may play a role in oocyte maturation, granulosa cell proliferation and death, and estradiol and progesterone production [105].

5.2. Leptin. Many authors are concordant on leptin playing a significant role in the onset and progression of puberty in humans. It is well known that congenital leptin deficiency, due to mutations in leptin gene or leptin receptor gene, cause early-onset obesity and absence of pubertal development [106]. At onset of puberty in healthy boys leptin concentrations rise by approximately $50 \%$ even before the increase in testosterone, LH, and FSH and then subsequently decline to baseline values [107-110].

In addition, nocturnal peaks in leptin secretion before puberty have been demonstrated in both rats and primates $[111,112]$. All these data imply a role for leptin especially in the onset of puberty $[113,114]$.

Leptin concentrations have been shown to rise persistently during puberty also between Tanner stages III and IV. In addition, the same authors showed a significant decrease of soluble leptin receptor concentrations (SOB-R) and subsequently a continuous rise in free leptin index (FLIratio between leptin and SOB-R) which are more evident during Tanner stages I and II. A rapid FLI rise from Tanner stage I to II might be therefore implicated in the onset of puberty and thelarche in females. These observations suggest that FLI may be a better predictor of pubertal onset and sexual maturation compared to serum leptin concentrations alone, which conversely reflects more sensitively body composition and could therefore be a better predictor of forthcoming menarche [115]. Moreover, recent molecular and genetic data on mouse models support a permissive role for leptin in the normal progression of pubertal development [116]. Indeed, numerous studies have shown how leptin may contribute to hypothalamic-pituitary-gonadal regulation, both at the central and gonadal levels [117].

At the central level, leptin has been shown to have facilitatory effects on $\mathrm{GnRH}$ secretion; leptin increases pulsatile activity of $\mathrm{GnRH}$ neurons in the hypothalamus in different species and in both sexes [116].
Leptin acts both on glutamatergic ventral premammillary nucleus (PMV) neurons and on GABAergic AgRP neurons in the arcuate nucleus, with a stimulatory effect for the first ones and an inhibitory effect on the second ones. These groups of neurons are both linked to $\mathrm{GnRH}$ and/or kisspeptin neurons, thus modulating the production of GnRH [116]. Therefore, leptin may have a crucial role in the control of the hypothalamic-pituitary-gonadal axis through the modulation of these opposite signals according to the nutritional status of the body. It is important to underline that the absence of leptin signal in one of these neuronal groups does not, however, prevent sexual development, suggesting a possible compensating effect of one group of neurons on the other. These observations confirm the role of leptin as a facilitatory agent in sexual maturation and pubertal onset. In addition to its action on the hypothalamus, leptin has also been shown to control gonadal activity. Indeed, several authors have demonstrated the expression of leptin receptor in both male and female gonadal tissues; in particular, the leptin receptor has been found to be expressed in ovarian follicular cells, including granulosa, theca, and interstitial cells, and in Leydig cells $[116,117]$. In vivo and in vitro studies showed how leptin reduces ovulation [118].

In the ovary, high leptin concentrations seem to have an inhibitory action on estradiol production and, therefore, block the maturation of dominant follicles and oocytes. Leptin also has a similar action in male gonadal tissue, with a dose-dependent inhibitory effect on testosterone production from Leydig cells as demonstrated in rats [119]. Therefore, leptin would have a bimodal action on the hypothalamicpituitary-gonadal axis: at low concentrations, such as in starvation states, it would have a permissive threshold effect on the central neuronal circuits and, at high concentrations, on the contrary, as in obese subjects, it would have an inhibitory action on the gonads [118].

5.3. Resistin and Visfatin. No data are available to date as to resistin and visfatin in relationship with pubertal development.

Concerning gonadal function, there is only one study from Rak-Mardyła et al. in which the authors suggest a potential autocrine and/or paracrine role for visfatin in the regulation of estrous cycle and ovarian follicles development in porcine [120].

In Table 3 we detail the role of adipokines in puberty and pubertal development including key hormonal factors and molecules.

\section{Adipokines in Growth and Pubertal Disorders}

6.1. Adipokines and Premature Pubarche. Premature pubarche is classically defined as the development of pubic hair before the age of 8 years in females and 9 years in males. The most common cause of this phenomenon is a premature activation of the adrenal cortex, a process, known as premature adrenarche, characterized by an increased production of adrenal androgens, especially DHEA, DHEA-S, and 
TABLE 3: Role of adipokines in puberty.

\begin{tabular}{lcc}
\hline Adipokine & GnRH, LH, and FSH & Estradiol (E2) and testosterone (T) \\
\hline Adiponectin & $\begin{array}{c}\text { AdipoR2 is regulated by the LH receptor } \\
\text { function via a cAMP dependent } \\
\text { mechanism [132]. }\end{array}$ & $\begin{array}{c}\text { T inhibits secretion from adipocytes. } \\
\text { E2 controls oocyte maturation and } \\
\text { granulosa cells cycle [104, 105]. }\end{array}$ \\
\hline $\begin{array}{l}\text { Leptin } \\
\text { Rises before LH and FSH surge and } \\
\text { subsequently declines promoting sexual } \\
\text { maturation and pubertal onset. } \\
\text { Induces secretion of GnRH and increases } \\
\text { pulsatile activity [116, 117]. }\end{array}$ & $\begin{array}{c}\text { Rises before T increase and subsequently } \\
\text { declines. }\end{array}$ \\
\hline Vesistin & Not described & $\begin{array}{c}\text { Reduces ovulation inhibiting E2 and T } \\
\text { production acting on Leydig cells } \\
{[118,119] .}\end{array}$ \\
\hline
\end{tabular}

androstenedione. The mechanisms underlying the development of premature adrenarche are still not well understood. Some authors have shown an association between premature pubarche and later development of insulin resistance, dyslipidemia, PCOS, and metabolic syndrome (especially in patients born small for gestational age); however, in most cases, it represents a variant of normal pubertal development $[95,121]$.

Adipokine patterns in girls with premature pubarche have been investigated, with few statistically significant data present in the literature and in some cases with conflicting results.

One study by Larqué et al. evaluated postprandial adiponectin response in girls with premature pubarche (PP) compared to controls; this work showed a significantly lower postprandial adiponectin area under the curve in PP girls, even after adjusting for BMI and age [122].

Teixeira et al. studied leptin concentrations in girls with premature pubarche, finding higher leptin levels compared to controls, independent of insulin and androgen concentrations [123].

We are not aware of any studies relating premature pubarche with resistin and visfatin.

\subsection{Adipokines and Constitutional Delay of Growth and} Puberty. Constitutional delay of growth and puberty (CDGP) is a condition characterized by a delay in the onset of pubertal development, representing a variant of the normal pubertal pattern without a defined endocrine abnormality. Data in the literature are overall still scarce, and basically only observational studies are available.

Leptin concentrations have been reported to be lower in adolescent boys with CDGP compared with regular and early maturers [124]. The authors further described a positive correlation between leptin, BMI, bone age, testicular volume, $\mathrm{FSH}, \mathrm{LH}$, and testosterone concentrations confirming previous findings.

Therefore, sexual immaturity in adolescents with CDGP seems to be characterized, at least in part, by decreased leptin concentrations [124].

6.3. Adipokines and Polycystic Ovarian Syndrome. Polycystic ovarian syndrome (PCOS) is one of the most common disorders in females, affecting approximately $15 \%$ of women during reproductive age [125]. It is classically characterized by three distinctive features: hyperandrogenism, ovarian dysfunction, and polycystic morphology pattern of ovaries on ultrasound scan [126]. A pivotal role in the pathophysiology of this syndrome is played by visceral adiposity and insulin resistance. Considering the importance of the adipokine milieu in modulating insulin sensitivity and hypothalamicpituitary-gonadal axis, many authors have suggested a central role for adipokines in the development of hyperandrogenism and infertility in PCOS. Obese women are more prone to developing PCOS, and considering that these subjects show per se increased plasma concentrations of adipokines as leptin and lower concentrations of adiponectin, it is difficult to verify an independent effect of adipokines in PCOS. The aim of this section is to summarize the role of several adipokines in the pathogenesis of PCOS [127].

The role of adiponectin in polycystic ovary syndrome is still debated. Several studies have reported that adiponectin levels in women with PCOS are lower compared to nonPCOS controls with comparable BMI. In vitro, adiponectin has been shown to inhibit androgen production, key enzymes involved in androgen pathways, and LH receptor gene expression from theca cells [128]. Moreover, in bovine theca cells, the knockdown of adiponectin receptor genes determined an increase in androstenedione secretion [105].

These observations suggested that fat cell metabolism may be linked to ovarian steroidogenesis through adiponectin secretion and that disruption of adiponectin and its pathway may play an important part in the onset of hyperandrogenism in PCOS.

In addition, several authors have reported a correlation between lower adiponectin concentrations and the insulin insensitivity observed in women with PCOS compared with controls [129].

Leptin has been thought to play a role in the onset of ovarian dysfunction in obese subjects, as previously mentioned; hyperleptinemia might interfere with estrogen production and maturation of dominant follicles [130]. However, most authors agree that there are no significant differences in leptin levels in women with PCOS compared with controls, even after correction for weight and BMI [131]. Table 4 summarizes the main findings published in the literature concerning the 
TABLE 4: Main findings published in the literature concerning the relationship between adiponectin, leptin and onset of PCOS.

\begin{tabular}{|c|c|c|c|c|}
\hline Author & $\begin{array}{c}\text { Adipokine } \\
\text { studied }\end{array}$ & Type of study & In vivo/species & Main conclusions \\
\hline $\begin{array}{l}\text { Comim et al. } \\
{[105]}\end{array}$ & Adiponectin & Case control & $\begin{array}{l}\text { In vitro/humans } \\
\text { and bovine }\end{array}$ & $\begin{array}{l}\text { There is strong evidence for a direct link } \\
\text { between fat cell metabolism and ovarian } \\
\text { steroidogenesis, suggesting that disruption of } \\
\text { adiponectin and/or its receptors plays a key role } \\
\text { in pathogenesis of hyperandrogenism in PCOS. }\end{array}$ \\
\hline $\begin{array}{l}\text { Toulis et al. } \\
\text { [129] }\end{array}$ & Adiponectin & Meta analysis & In vivo/humans & $\begin{array}{c}\text { Adiponectin levels seem to be lower in women } \\
\text { with PCOS compared with non-PCOS } \\
\text { controls. } \\
\text { Low levels of adiponectin in PCOS are } \\
\text { probably related to insulin resistance but not to } \\
\text { testosterone levels. } \\
\text { Total adiponectin should not be used as a } \\
\text { biomarker of PCOS severity. } \\
\text { Further investigations are needed to } \\
\text { understand the role of high molecular weight } \\
\text { adiponectin levels in PCOS. }\end{array}$ \\
\hline $\begin{array}{l}\text { Svendsen et al. } \\
{[131]}\end{array}$ & $\begin{array}{l}\text { Adiponectin, } \\
\text { leptin }\end{array}$ & Cross-sectional & In vivo/humans & $\begin{array}{l}\text { PCOS does not appear to have an independent } \\
\text { effect on the adipose expression of leptin, } \\
\text { adiponectin, and IL- } 6 \text { or the circulating } \\
\text { adipocytokines. }\end{array}$ \\
\hline Li et al. [127] & Leptin & Case control & In vivo/humans & $\begin{array}{l}\text { A significant association was found between } \\
\text { the Pro1019Pro in LEPR gene and PCOS, and a } \\
\text { highly significant association was found } \\
\text { between the Gln223Arg in LEPR gene and } \\
\text { PCOS. }\end{array}$ \\
\hline
\end{tabular}

relationship between adiponectin and leptin and onset of PCOS.

The contribution of other adipokines, such as resistin and visfatin, to the pathophysiology of PCOS has been largely debated, but there is no conclusive evidence in the literature for a significant role.

Some authors have studied resistin serum concentrations in PCOS, but the results of these studies at this time remain conflicting $[125,131]$.

Patients with type 2 diabetes, women with gestational diabetes, and women with PCOS tend to have higher plasma visfatin concentrations compared with controls, which would confirm its role in the determinism of insulin resistance and thus a potential role in the control of ovarian steroidogenesis.

\section{Conclusions}

Recent studies have focused on the production of adipokines not only by the adipose tissue but also by other organs such as placenta, ovaries, peripheral-blood mononuclear cells, liver, muscle, kidney, heart, and bone marrow, introducing the concept of a more pleiotropic action of these hormones. The regulation of insulin sensitivity remains, however, central to their action, and tightly related to pre- and post-natal longitudinal growth and weight increase, pubertal development, and pubertal disorders.
Many of these aspects, however, remain not entirely understood and need further investigation.

Summarizing the main findings to date consists in adiponectin being an upregulator of insulin and energy balance. Leptin mediates mainly food intake, liver glucose production, gonadotropin secretion, suppression of lipogenesis in adipose tissue, and modulation of immune responses. Circulating levels of leptin are related to adipose mass. Resistin is likely to have an inhibitory effect on adipose conversion, acting as a feedback regulator of adipogenesis and adipose tissue. Recently, visfatin has been described as a protein with insulin-like functions.

There is evidence that these adipokines are important in placental and fetal growth, programming of insulin sensitivity, and present relationships with birth weight.

Pubertal development is physiologically characterized by an increase in adipose mass and changes in adipose tissue distribution. Many authors are concordant on a significant role of leptin in pubertal initiation and progression in humans. In healthy lean males, but not in females, adiponectin concentrations significantly reduce during puberty, with lower adiponectin levels in adolescent boys compared to girls.

Timing and progression of puberty is related to being born small or appropriate for gestational age and preterm or full-term, and size at birth is related mainly to premature pubarche, an earlier onset of pubertal development and menarche, and subsequent development of PCOS. 
Some data show that adipokines concentrations are different in most disorders of puberty, although at present data they are not definitive and not always consistent. Altogether, data are yet scarce and further studies are warranted.

\section{Competing Interests}

The authors declare that there is no conflict of interests regarding the publication of this paper.

\section{References}

[1] U. Meier and A. M. Gressner, "Endocrine regulation of energy metabolism: review of pathobiochemical and clinical chemical aspects of leptin, ghrelin, adiponectin, and resistin," Clinical Chemistry, vol. 50, no. 9, pp. 1511-1525, 2004.

[2] D. B. Campos, M.-F. Palin, V. Bordignon, and B. D. Murphy, "The 'beneficial' adipokines in reproduction and fertility," International Journal of Obesity, vol. 32, no. 2, pp. 223-231, 2008.

[3] S. B. Lecke, D. M. Morsch, and P. M. Spritzer, "Leptin and adiponectin in the female life course," Brazilian Journal of Medical and Biological Research, vol. 44, no. 5, pp. 381-387, 2011.

[4] D. D. Briana and A. Malamitsi-Puchner, "The role of adipocytokines in fetal growth," Annals of the New York Academy of Sciences, vol. 1205, pp. 82-87, 2010.

[5] A. D. von Frankenberg, F. V. do Nascimento, L. E. Gatelli et al., "Major components of metabolic syndrome and adiponectin levels: a cross-sectional study," Diabetology and Metabolic Syndrome, vol. 6, no. 1, article 26, 2014.

[6] T. Yamauchi and T. Kadowaki, "Physiological and pathophysiological roles of adiponectin and adiponectin receptors in the integrated regulation of metabolic and cardiovascular diseases," International Journal of Obesity, vol. 32, supplement 7, pp. S13S18, 2008.

[7] A. Smerieri, M. Petraroli, L. Montanini, C. Sartori, S. Bernasconi, and M. E. Street, "Association of placental insulin, total and activated insulin receptor contents, cortisol and IL-6 concentrations with human birth weight and length: pilot study," Journal of Biological Regulators and Homeostatic Agents, vol. 26, no. 4, pp. 693-699, 2012.

[8] M. E. Street, C. Volta, M. A. Ziveri, I. Viani, and S. Bernasconi, "Markers of insulin sensitivity in placentas and cord serum of intrauterine growth-restricted newborns," Clinical Endocrinology, vol. 71, no. 3, pp. 394-399, 2009.

[9] M. E. Street, E. Grossi, C. Volta, E. Faleschini, and S. Bernasconi, "Placental determinants of fetal growth: identification of key factors in the insulin-like growth factor and cytokine systems using artificial neural networks," BMC Pediatrics, vol. 8, article 24, 2008.

[10] M. E. Street, P. Seghini, S. Feini et al., "Changes in interleukin6 and IGF system and their relationships in placenta and cord blood in newborns with fetal growth restriction compared with controls," European Journal of Endocrinology, vol. 155, no. 4, pp. 567-574, 2006.

[11] M. E. Street, I. Viani, M. A. Ziveri, C. Volta, A. Smerieri, and S. Bernasconi, "Impairment of insulin receptor signal transduction in placentas of intra-uterine growth-restricted newborns and its relationship with fetal growth," European Journal of Endocrinology, vol. 164, no. 1, pp. 45-52, 2011.
[12] A. Dunaif, "Insulin resistance and the polycystic ovary syndrome: mechanism and implications for pathogenesis," Endocrine Reviews, vol. 18, no. 6, pp. 774-800, 1997.

[13] R. S. Legro, D. Finegood, and A. Dunaif, "A fasting glucose to insulin ratio is a useful measure of insulin sensitivity in women with polycystic ovary syndrome," Journal of Clinical Endocrinology and Metabolism, vol. 83, no. 8, pp. 2694-2698, 1998.

[14] T. M. Barber, M. I. McCarthy, J. A. H. Wass, and S. Franks, "Obesity and polycystic ovary syndrome," Clinical Endocrinology, vol. 65, no. 2, pp. 137-145, 2006.

[15] L. Lazar, U. Pollak, O. Kalter-Leibovici, A. Pertzelan, and M. Phillip, "Pubertal course of persistently short children born small for gestational age (SGA) compared with idiopathic short children born appropriate for gestational age (AGA)," European Journal of Endocrinology, vol. 149, no. 5, pp. 425-432, 2003.

[16] L. Ibáñez, K. Ong, D. B. Dunger, and F. de Zegher, "Early development of adiposity and insulin resistance after catch-up weight gain in small-for-gestational-age children," The Journal of Clinical Endocrinology \& Metabolism, vol. 91, no. 6, pp. 21532158, 2006.

[17] J. E. Caminos, R. Nogueiras, R. Gallego et al., "Expression and regulation of adiponectin and receptor in human and rat placenta," The Journal of Clinical Endocrinology \& Metabolism, vol. 90, no. 7, pp. 4276-4286, 2005.

[18] J. Chen, B. Tan, E. Karteris et al., "Secretion of adiponectin by human placenta: differential modulation of adiponectin and its receptors by cytokines," Diabetologia, vol. 49, no. 6, pp. 1292 1302, 2006.

[19] H. S. Berner, S. P. Lyngstadaas, A. Spahr et al., "Adiponectin and its receptors are expressed in bone-forming cells," Bone, vol. 35, no. 4, pp. 842-849, 2004.

[20] R. Piñeiro, M. J. Iglesias, R. Gallego et al., "Adiponectin is synthesized and secreted by human and murine cardiomyocytes," FEBS Letters, vol. 579, no. 23, pp. 5163-5169, 2005.

[21] J. Thundyil, D. Pavlovski, C. G. Sobey, and T. V. Arumugam, "Adiponectin receptor signalling in the brain," British Journal of Pharmacology, vol. 165, no. 2, pp. 313-327, 2012.

[22] M. J. Yoon, G. Y. Lee, J.-J. Chung, Y. H. Ahn, S. H. Hong, and J. B. Kim, "Adiponectin increases fatty acid oxidation in skeletal muscle cells by sequential activation of AMP-activated protein kinase, p38 mitogen-activated protein kinase, and peroxisome proliferator-activated receptor $\alpha$, Diabetes, vol. 55, no. 9, pp. 2562-2570, 2006.

[23] P. Chedid, M. Hurtado-Nedelec, B. Marion-Gaber et al., "Adiponectin and its globular fragment differentially modulate the oxidative burst of primary human phagocytes," The American Journal of Pathology, vol. 180, no. 2, pp. 682-692, 2012.

[24] R. Faulhaber-Walter, "Adipokines and central control in adenosine A1 receptor dependent glucose metabolism," Adipocyte, vol. 1, no. 2, pp. 108-111, 2014.

[25] M. Beylot, C. Pinteur, and O. Peroni, "Expression of the adiponectin receptors AdipoR1 and AdipoR2 in lean rats and in obese Zucker rats," Metabolism, vol. 55, no. 3, pp. 396-401, 2006.

[26] T. Kadowaki, T. Yamauchi, N. Kubota, K. Hara, K. Ueki, and $\mathrm{K}$. Tobe, "Adiponectin and adiponectin receptors in insulin resistance, diabetes, and the metabolic syndrome," The Journal of Clinical Investigation, vol. 116, no. 7, pp. 1784-1792, 2006. 
[27] A. S. Lihn, S. B. Pedersen, and B. Richelsen, "Adiponectin: action, regulation and association to insulin sensitivity," Obesity Reviews, vol. 6, no. 1, pp. 13-21, 2005.

[28] T. Yamauchi, J. Kamon, H. Waki et al., "The fat-derived hormone adiponectin reverses insulin resistance associated with both lipoatrophy and obesity," Nature Medicine, vol. 7, no. 8, pp. 941-946, 2001.

[29] H. Zhou, X. Song, M. Briggs et al., "Adiponectin represses gluconeogenesis independent of insulin in hepatocytes," Biochemical and Biophysical Research Communications, vol. 338, no. 2, pp. 793-799, 2005.

[30] N. Ouchi, S. Kihara, Y. Arita et al., "Adiponectin, an adipocytederived plasma protein, inhibits endothelial NF- $\kappa \mathrm{B}$ signaling through a cAMP-dependent pathway," Circulation, vol. 102, no. 11, pp. 1296-1301, 2000.

[31] N. Maeda, I. Shimomura, K. Kishida et al., "Diet-induced insulin resistance in mice lacking adiponectin/ACRP30," Nature Medicine, vol. 8, no. 7, pp. 731-737, 2002.

[32] T. Yokota, K. Oritani, I. Takahashi et al., "Adiponectin, a new member of the family of soluble defense collagens, negatively regulates the growth of myelomonocytic progenitors and the functions of macrophages," Blood, vol. 96, no. 5, pp. 1723-1732, 2000.

[33] A. M. Wolf, D. Wolf, H. Rumpold, B. Enrich, and H. Tilg, "Adiponectin induces the anti-inflammatory cytokines IL-10 and IL-1RA in human leukocytes," Biochemical and Biophysical Research Communications, vol. 323, no. 2, pp. 630-635, 2004.

[34] C. J. Ashworth, N. Hoggard, L. Thomas, J. G. Mercer, J. M. Wallace, and R. G. Lea, "Placental leptin," Reviews of Reproduction, vol. 5, no. 1, pp. 18-24, 2000.

[35] L. Ghizzoni, G. Mastorakos, M. E. Street et al., "Leptin, cortisol, and GH secretion interactions in short normal prepubertal children," The Journal of Clinical Endocrinology \& Metabolism, vol. 86, no. 8, pp. 3729-3734, 2001.

[36] S. Uotani, C. Bjørbæk, J. Tornøe, and J. S. Flier, "Functional properties of leptin receptor isoforms: internalization and degradation of leptin and ligand-induced receptor downregulation," Diabetes, vol. 48, no. 2, pp. 279-286, 1999.

[37] T. Kelesidis and C. S. Mantzoros, "The emerging role of leptin in humans," Pediatric Endocrinology Reviews, vol. 3, no. 3, pp. 239-248, 2006.

[38] M. D. Klok, S. Jakobsdottir, and M. L. Drent, "The role of leptin and ghrelin in the regulation of food intake and body weight in humans: a review," Obesity Reviews, vol. 8, no. 1, pp. 21-34, 2007.

[39] R. M. Fenichel, J. E. Dominguez, L. Mayer, B. T. Walsh, C. Boozer, and M. P. Warren, "Leptin levels and luteinizing hormone pulsatility in normal cycling women and their relationship to daily changes in metabolic rate," Fertility and Sterility, vol. 90, no. 4, pp. 1161-1168, 2008.

[40] J. Licinio, A. B. Negrão, C. Mantzoros et al., "Synchronicity of frequently sampled, 24-h concentrations of circulating leptin, luteinizing hormone, and estradiol in healthy women," Proceedings of the National Academy of Sciences of the United States of America, vol. 95, no. 5, pp. 2541-2546, 1998.

[41] A. Ewart-Toland, K. Mounzih, J. Qiu, and F. F. Chehab, "Effect of the genetic background on the reproduction of leptin-deficient obese mice," Endocrinology, vol. 140, no. 2, pp. 732-738, 1999.

[42] S. D. Patel, M. W. Rajala, L. Rossetti, P. E. Scherer, and L. Shapiro, "Disulfide-dependent multimeric assembly of resistin family hormones," Science, vol. 304, no. 5674, pp. 1154-1158, 2004.
[43] P. C. Tsiotra, E. Boutati, G. Dimitriadis, and S. A. Raptis, "High insulin and leptin increase resistin and inflammatory cytokine production from human mononuclear cells," BioMed Research International, vol. 2013, Article ID 487081, 10 pages, 2013.

[44] S.-D. Qi, Z.-L. He, Y. Chen et al., "Relevance and clinical significance of serum resistin level in obese T2DM rhesus monkey models," Experimental and Clinical Endocrinology and Diabetes, vol. 123, no. 8, pp. 508-513, 2015.

[45] K. Takemoto, R. J. Deckelbaum, I. Saito et al., "Adiponectin/resistin levels and insulin resistance in children: a four country comparison study," International Journal of Pediatric Endocrinology, vol. 2015, article 2, 2015.

[46] Y. Benomar, A. Gertler, P. De Lacy et al., "Central resistin overexposure induces insulin resistance through toll-like receptor 4," Diabetes, vol. 62, no. 1, pp. 102-114, 2013.

[47] G. Ntaios, N. K. Gatselis, K. Makaritsis, and G. N. Dalekos, "Adipokines as mediators of endothelial function and atherosclerosis," Atherosclerosis, vol. 227, no. 2, pp. 216-221, 2013.

[48] C. Y. Jiang, W. Wang, J. X. Tang, and Z. R. Yuan, “The adipocytokine resistin stimulates the production of proinflammatory cytokines TNF- $\alpha$ and IL- 6 in pancreatic acinar cells via NF- $\kappa \mathrm{B}$ activation," Journal of Endocrinological Investigation, vol. 36, no. 11, pp. 986-992, 2013.

[49] E. Senateş, Y. Colak, A. Yeşil et al., "Circulating resistin is elevated in patients with non-alcoholic fatty liver disease and is associated with steatosis, portal inflammation, insulin resistance and nonalcoholic steatohepatitis scores," Minerva Medica, vol. 103, no. 5, pp. 369-376, 2012.

[50] C. Shen, C.-Y. Zhao, W. Wang et al., "The relationship between hepatic resistin overexpression and inflammation in patients with nonalcoholic steatohepatitis," BMC Gastroenterology, vol. 14, article 39, 2014.

[51] B. Samal, Y. Sun, G. Stearns, C. Xie, S. Suggs, and I. McNiece, "Cloning and characterization of the cDNA encoding a novel human pre-B-cell colony-enhancing factor," Molecular and Cellular Biology, vol. 14, no. 2, pp. 1431-1437, 1994.

[52] E. Adeghate, "Visfatin: Structure, function and relation to diabetes mellitus and other dysfunctions," Current Medicinal Chemistry, vol. 15, no. 18, pp. 1851-1862, 2008.

[53] H. J. Kim, S. Y. Park, Y. J. Choi, S. J. Han, K. W. Lee, and D. J. Kim, "Differential significance of plasma visfatin concentrations according to adiposity in children and adolescents," Hormone Research in Paediatrics, vol. 79, no. 4, pp. 208-213, 2013.

[54] S. Araki, K. Dobashi, K. Kubo et al., "Plasma visfatin concentration as a surrogate marker for visceral fat accumulation in obese children," Obesity, vol. 16, no. 2, pp. 384-388, 2008.

[55] U. Gümüş, A. I. Güzel, H. O. Topcu, H. Timur, N. Yilmaz, and N. Danişman, "Plasma visfatin levels in adolescents with polycystic ovary syndrome: a prospective case-control study," Journal of Pediatric and Adolescent Gynecology, vol. 28, no. 4, pp. 249-253, 2016.

[56] M. Nourbakhsh, M. Nourbakhsh, Z. Gholinejad, and M. Razzaghy-Azar, "Visfatin in obese children and adolescents and its association with insulin resistance and metabolic syndrome," Scandinavian Journal of Clinical and Laboratory Investigation, vol. 75, no. 2, pp. 183-188, 2015.

[57] G. Valsamakis, S. Kumar, G. Creatsas, and G. Mastorakos, "The effects of adipose tissue and adipocytokines in human pregnancy," Annals of the New York Academy of Sciences, vol. 1205, pp. 76-81, 2010. 
[58] A. A. Houde, M. F. Hivert, and L. Bouchard, "Fetal epigenetic programming of adipokines," Adipocyte, vol. 2, no. 1, pp. 41-46, 2013.

[59] E. H. Yeung, A. C. McLain, N. Anderson et al., "Newborn adipokines and birth outcomes," Paediatric and Perinatal Epidemiology, vol. 29, no. 4, pp. 317-325, 2015.

[60] Y. Kotani, I. Yokota, S. Kitamura, J. Matsuda, E. Naito, and Y. Kuroda, "Plasma adiponectin levels in newborns are higher that those in adults and positively correlated with birth weight," Clinical Endocrinology, vol. 61, no. 4, pp. 418-423, 2004.

[61] E. Sivan, S. Mazaki-Tovi, C. Pariente et al., "Adiponectin in human cord blood: relation to fetal birth weight and gender," Journal of Clinical Endocrinology and Metabolism, vol. 88, no. 12, pp. 5656-5660, 2003.

[62] S. Mazaki-Tovi, H. Kanety, C. Pariente, R. Hemi, E. Schiff, and E. Sivan, "Cord blood adiponectin in large-for-gestational age newborns," American Journal of Obstetrics \& Gynecology, vol. 193, no. 3, part 2, pp. 1238-1242, 2005.

[63] S. Mazaki-Tovi, H. Kanety, C. Pariente et al., "Cord blood adiponectin and infant growth at one year," Journal of Pediatric Endocrinology and Metabolism, vol. 24, no. 7-8, pp. 411-418, 2011.

[64] C. Mantzoros, E. Petridou, D.-M. Alexe et al., "Serum adiponectin concentrations in relation to maternal and perinatal characteristics in newborns," European Journal of Endocrinology, vol. 151, no. 6, pp. 741-746, 2004.

[65] S. Cianfarani, C. Martinez, A. Maiorana, G. Scirè, G. L. Spadoni, and S. Boemi, "Adiponectin levels are reduced in children born small for gestational age and are inversely related to postnatal catch-up growth," Journal of Clinical Endocrinology and Metabolism, vol. 89, no. 3, pp. 1346-1351, 2004.

[66] S. Mazaki-Tovi, H. Kanety, C. Pariente et al., "Adiponectin and leptin concentrations in dichorionic twins with discordant and concordant growth," Journal of Clinical Endocrinology and Metabolism, vol. 94, no. 3, pp. 892-898, 2009.

[67] K. Oshima, A. Nampei, M. Matsuda et al., "Adiponectin increases bone mass by suppressing osteoclast and activating osteoblast," Biochemical and Biophysical Research Communications, vol. 331, no. 2, pp. 520-526, 2005.

[68] L. Ibáñez, G. Sebastiani, A. Lopez-Bermejo, M. Díaz, M. D. Gómez-Roig, and F. de Zegher, "Gender specificity of body adiposity and circulating adiponectin, visfatin, insulin, and insulin growth factor-I at term birth: relation to prenatal growth," The Journal of Clinical Endocrinology \& Metabolism, vol. 93, no. 7, pp. 2774-2778, 2008.

[69] L. Bouchard, M.-F. Hivert, S.-P. Guay, J. St-Pierre, P. Perron, and D. Brisson, "Placental adiponectin gene DNA methylation levels are associated with mothers' blood glucose concentration," Diabetes, vol. 61, no. 5, pp. 1272-1280, 2012.

[70] N. Hoggard, P. Haggarty, L. Thomas, and R. G. Lea, "Leptin expression in placental and fetal tissues: does leptin have a functional role?" Biochemical Society Transactions, vol. 29, part 2, pp. 57-63, 2001.

[71] A. J. Forhead and A. L. Fowden, "The hungry fetus? Role of leptin as a nutritional signal before birth," The Journal of Physiology, vol. 587, no. 6, pp. 1145-1152, 2009.

[72] C. Schubring, W. Kiess, P. Englaro et al., "Levels of leptin in maternal serum, amniotic fluid, and arterial and venous cord blood: relation to neonatal and placental weight," Journal of Clinical Endocrinology and Metabolism, vol. 82, no. 5, pp. 14801483, 1997.
[73] M. Pighetti, G. A. Tommaselli, A. D’Elia et al., "Maternal serum and umbilical cord blood leptin concentrations with fetal growth restriction," Obstetrics and Gynecology, vol. 102, no. 3, pp. 535-543, 2003.

[74] R. G. Lea, D. Howe, L. T. Hannah, O. Bonneau, L. Hunter, and N. Hoggard, "Placental leptin in normal, diabetic and fetal growthretarded pregnancies," Molecular Human Reproduction, vol. 6, no. 8, pp. 763-769, 2000.

[75] P.-J. Tsai, C.-H. Yu, S.-P. Hsu et al., "Cord plasma concentrations of adiponectin and leptin in healthy term neonates: positive correlation with birthweight and neonatal adiposity," Clinical Endocrinology, vol. 61, no. 1, pp. 88-93, 2004.

[76] M. M. Vela-Huerta, E. U. San Vicente-Santoscoy, J. M. GuizarMendoza, N. Amador-Licona, C. Aldana-Valenzuela, and J. Hernnández, "Leptin, insulin, and glucose serum levels in large-for-gestational-age infants of diabetic and non-diabetic mothers," Journal of Pediatric Endocrinology and Metabolism, vol. 21, no. 1, pp. 17-22, 2008.

[77] H. Mise, N. Sagawa, T. Matsumoto et al., "Augmented placental production of leptin in preeclampsia: possible involvement of placental hypoxia," Journal of Clinical Endocrinology and Metabolism, vol. 83, no. 9, pp. 3225-3229, 1998.

[78] H. Mise, S. Yura, H. Itoh et al., "The relationship between maternal plasma leptin levels and fetal growth restriction," Endocrine Journal, vol. 54, no. 6, pp. 945-951, 2007.

[79] J.-M. Atègbo, O. Grissa, A. Yessoufou et al., "Modulation of adipokines and cytokines in gestational diabetes and macrosomia," The Journal of Clinical Endocrinology \& Metabolism, vol. 91, no. 10, pp. 4137-4143, 2006.

[80] L. Bouchard, S. Thibaul, S. P. Guay et al., "Leptin gene epigenetic adaption to impaired glucose metabolism during pregnancy," Diabetes Care, vol. 33, no. 11, pp. 2436-2441, 2010.

[81] S.-M. Ruchat, M.-F. Hivert, and L. Bouchard, "Epigenetic programming of obesity and diabetes by in utero exposure to gestational diabetes mellitus," Nutrition Reviews, vol. 71, supplement 1, pp. S88-S94, 2013.

[82] S. Yura, N. Sagawa, H. Itoh et al., "Resistin is expressed in the human placenta," Journal of Clinical Endocrinology and Metabolism, vol. 88, no. 3, pp. 1394-1397, 2003.

[83] M. Lappas, K. Yee, M. Permezel, and G. E. Rice, "Release and regulation of leptin, resistin and adiponectin from human placenta, fetal membranes, and maternal adipose tissue and skeletal muscle from normal and gestational diabetes mellituscomplicated pregnancies," Journal of Endocrinology, vol. 186, no. 3, pp. 457-465, 2005.

[84] F. Savino, M. Sorrenti, S. Benetti, M. M. Lupica, S. A. Liguori, and R. Oggero, "Resistin and leptin in breast milk and infants in early life," Early Human Development, vol. 88, no. 10, pp. 779$782,2012$.

[85] N. Vitoratos, A. Dimitrakaki, N. F. Vlahos et al., "Maternal and umbilical resistin levels do not correlate with infant birth weight either in normal pregnancies and or in pregnancies complicated with gestational diabetes," Journal of MaternalFetal and Neonatal Medicine, vol. 23, no. 9, pp. 1019-1023, 2010.

[86] T. F. Lobo, M. R. Torloni, B. Y. Gueuvoghlanian-Silva, R. Mattar, and S. Daher, "Resistin concentration and gestational diabetes: a systematic review of the literature," Journal of Reproductive Immunology, vol. 97, no. 1, pp. 120-127, 2013.

[87] A. Malamitsi-Puchner, D. D. Briana, M. Boutsikou, E. Kouskouni, D. Hassiakos, and D. Gourgiotis, "Perinatal circulating 
visfatin levels in intrauterine growth restriction," Pediatrics, vol. 119, no. 6, pp. e1314-e1318, 2007.

[88] W. Hu, Z. Wang, H. Wang, H. Huang, and M. Dong, "Serum visfatin levels in late pregnancy and pre-eclampsia," Acta Obstetricia et Gynecologica Scandinavica, vol. 87, no. 4, pp. 413-418, 2008.

[89] P. Saenger, P. Czernichow, I. Hughes, and E. O. Reiter, "Small for gestational age: short stature and beyond," Endocrine Reviews, vol. 28, no. 2, pp. 219-251, 2007.

[90] J. Karlberg and K. Albertsson-Wikland, "Growth in full-term small-for-gestational-age infants: from birth to final height," Pediatric Research, vol. 38, no. 5, pp. 733-739, 1995.

[91] J. Leger, C. Levy-Marchal, J. Bloch et al., "Reduced final height and indications for insulin resistance in 20 year olds born small for gestational age: regional cohort study," The British Medical Journal, vol. 315, no. 7104, pp. 341-347, 1997.

[92] K. Albertsson-Wikland and J. Karlberg, "Natural growth in children born small for gestational age with and without catchup growth," Acta Paediatrica Supplement, vol. 399, pp. 64-71, 1994.

[93] K. Albertsson-Wikland, M. Boguszewski, and J. Karlberg, "Children born small-for-gestational age: postnatal growth and hormonal status," Hormone Research, vol. 49, no. 2, pp. 7-13, 1998.

[94] K. K. Ong, N. Potau, C. J. Petry et al., "Opposing influences of prenatal and postnatal weight gain on adrenarche in normal boys and girls," The Journal of Clinical Endocrinology \& Metabolism, vol. 89, no. 6, pp. 2647-2651, 2004.

[95] L. Ibáñez, N. Potau, I. Francois, and F. de Zegher, "Precocious pubarche, hyperinsulinism, and ovarian hyperandrogenism in girls: relation to reduced fetal growth," The Journal of Clinical Endocrinology \& Metabolism, vol. 83, no. 10, pp. 3558-3562, 1998.

[96] K. A. Neville and J. L. Walker, "Precocious pubarche is associated with SGA, prematurity, weight gain, and obesity," Archives of Disease in Childhood, vol. 90, no. 3, pp. 258-261, 2005.

[97] L. Ibáñez, R. Díaz, A. López-Bermejo, and M. V. Marcos, “Clinical spectrum of premature pubarche: links to metabolic syndrome and ovarian hyperandrogenism," Reviews in Endocrine and Metabolic Disorders, vol. 10, no. 1, pp. 63-76, 2009.

[98] J. Karlberg, C.-W. Kwan, L. Gelander, and K. AlbertssonWikland, "Pubertal growth assessment," Hormone Research, vol. 60, no. 1, pp. 27-35, 2003.

[99] I. Persson, F. Ahlsson, U. Ewald et al., "Influence of perinatal factors on the onset of puberty in boys and girls: implications for interpretation of link with risk of long term diseases," American Journal of Epidemiology, vol. 150, no. 7, pp. 747-755, 1999.

[100] S. Chaudhari, M. Otiv, M. Hoge, A. Pandit, and A. Mote, "Growth and sexual maturation of low birth weight infants at early adolescence," Indian Pediatrics, vol. 45, no. 3, pp. 191-198, 2008.

[101] D. M. Sloboda, R. Hart, D. A. Doherty, C. E. Pennell, and M. Hickey, "Age at menarche: influences of prenatal and postnatal growth," The Journal of Clinical Endocrinology \& Metabolism, vol. 92, no. 1, pp. 46-50, 2007.

[102] S. K. Bhargava, S. Ramji, U. Srivastava et al., "Growth and sexual maturation of low birth weight children: a 14 year follow up," Indian Pediatrics, vol. 32, no. 9, pp. 963-970, 1995.

[103] T. P. Combs, A. H. Berg, M. W. Rajala et al., "Sexual differentiation, pregnancy, calorie restriction, and aging affect the adipocyte-specific secretory protein adiponectin," Diabetes, vol. 52, no. 2, pp. 268-276, 2003.

[104] A. Böttner, J. Kratzsch, G. Müller et al., "Gender differences of adiponectin levels develop during the progression of puberty and are related to serum androgen levels," The Journal of Clinical Endocrinology \& Metabolism, vol. 89, no. 8, pp. 4053-4061, 2004.

[105] F. V. Comim, K. Hardy, and S. Franks, "Adiponectin and its receptors in the ovary: further evidence for a link between obesity and hyperandrogenism in polycystic ovary syndrome," PLoS ONE, vol. 8, no. 11, Article ID e80416, 2013.

[106] C. F. Elias, "Leptin action in pubertal development: recent advances and unanswered questions," Trends in Endocrinology and Metabolism, vol. 23, no. 1, pp. 9-15, 2012.

[107] C. S. Mantzoros, J. S. Flier, and A. D. Rogol, "A longitudinal assessment of hormonal and physical alterations during normal puberty in boys. V. Rising leptin levels may signal the onset of puberty," The Journal of Clinical Endocrinology \& Metabolism, vol. 82, no. 4, pp. 1066-1070, 1997.

[108] W. F. Blum, P. Englaro, S. Hanitsch et al., "Plasma leptin levels in healthy children and adolescents: dependence on body mass index, body fat mass, gender, pubertal stage, and testosterone," The Journal of Clinical Endocrinology \& Metabolism, vol. 82, no. 9, pp. 2904-2910, 1997.

[109] P. E. Clayton, M. S. Gill, C. M. Hall, V. Tillmann, A. J. Whatmore, and D. A. Price, "Serum leptin through childhood and adolescence," Clinical Endocrinology, vol. 46, no. 6, pp. 727733, 1997.

[110] R. V. Garcia-Mayor, M. A. Andrade, M. Rios, M. Lage, C. Dieguez, and F. F. Casanueva, "Serum leptin levels in normal children: relationship to age, gender, body mass index, pituitary-gonadal hormones, and pubertal stage," The Journal of Clinical Endocrinology \& Metabolism, vol. 82, no. 9, pp. 28492855, 1997.

[111] S. Nagatani, P. Guthikonda, and D. L. Foster, "Appearance of a nocturnal peak of leptin secretion in the pubertal rat," Hormones and Behavior, vol. 37, no. 4, pp. 345-352, 2000.

[112] K. J. Suter, C. R. Pohl, and M. E. Wilson, "Circulating concentrations of nocturnal leptin, growth hormone, and insulin-like growth factor-I increase before the onset of puberty in agonadal male monkeys: potential signals for the initiation of puberty," The Journal of Clinical Endocrinology \& Metabolism, vol. 85, no. 2, pp. 808-814, 2000.

[113] M. B. Horlick, M. Rosenbaum, M. Nicolson et al., "Effect of puberty on the relationship between circulating leptin and body composition," Journal of Clinical Endocrinology and Metabolism, vol. 85, no. 7, pp. 2509-2518, 2000.

[114] J. M. Castellano, A. H. Bentsen, M. A. Sánchez-Garrido et al., "Early metabolic programming of puberty onset: impact of changes in postnatal feeding and rearing conditions on the timing of puberty and development of the hypothalamic kisspeptin system," Endocrinology, vol. 152, no. 9, pp. 33963408, 2011.

[115] H.-J. Li, C.-Y. Ji, W. Wang, and Y.-H. Hu, "A twin study for serum leptin, soluble leptin receptor, and free insulin-like growth factor-I in pubertal females," Journal of Clinical Endocrinology and Metabolism, vol. 90, no. 6, pp. 3659-3664, 2005.

[116] C. F. Elias and D. Purohit, "Leptin signaling and circuits in puberty and fertility," Cellular and Molecular Life Sciences, vol. 70, no. 5, pp. 841-862, 2013. 
[117] S. Moschos, J. L. Chan, and C. S. Mantzoros, "Leptin and reproduction: a review," Fertility and Sterility, vol. 77, no. 3, pp. 433-444, 2002.

[118] P. S. Duggal, K. H. Van Der Hoek, C. R. Milner et al., "The in vivo and in vitro effects of exogenous leptin on ovulation in the rat," Endocrinology, vol. 141, no. 6, pp. 1971-1976, 2000.

[119] M. Caprio, A. M. Isidori, A. R. Carta, C. Moretti, M. L. Dufau, and A. Fabbri, "Expression of functional leptin receptors in rodent Leydig cells," Endocrinology, vol. 140, no. 11, pp. 49394947, 1999.

[120] A. Rak-Mardyła, M. Duda, and E. Gregoraszczuk, "A role for resistin in the ovary during the estrous cycle," Hormone and Metabolic Research, vol. 46, no. 7, pp. 493-498, 2014.

[121] P. Saenger and J. DiMartino-Nardi, "Premature adrenarche," Journal of Endocrinological Investigation, vol. 24, no. 9, pp. 724733, 2001.

[122] E. Larqué, M. Gil-Campos, I. Villada, M. Ramírez-Tortosa, R. Cañete, and Á. Gil, "Postprandial plasma adiponectin response is reduced in prepubertal premature pubarche girls," Metabolism, vol. 59, no. 9, pp. 1319-1326, 2010.

[123] R. J. Teixeira, D. Ginzbarg, J. Rodrigues Freitas, G. Fucks, C. M. Silva, and M. A. N. Bordallo, "Serum leptin levels in premature pubarche and prepubertal girls with and without obesity," Journal of Pediatric Endocrinology and Metabolism, vol. 17, no. 10, pp. 1393-1398, 2004.

[124] M. S. Gill, C. M. Hall, V. Tillmann, and P. E. Clayton, "Constitutional delay in growth and puberty (CDGP) is associated with hypoleptinaemia," Clinical Endocrinology, vol. 50, no. 6, pp. 721726, 1999.

[125] X. Chen, X. Jia, J. Qiao, Y. Guan, and J. Kang, "Adipokines in reproductive function: a link between obesity and polycystic ovary syndrome," Journal of Molecular Endocrinology, vol. 50, no. 2, pp. R21-R37, 2013.

[126] The Rotterdam ESHRE/ASRM-Sponsored PCOS Consensus Workshop Group, "Revised 2003 consensus on diagnostic criteria and long-term health risks related to polycystic ovary syndrome," Fertility and Sterility, vol. 81, no. 1, pp. 19-25, 2004.

[127] L. Li, K.-J. Lee, B.-C. Choi, and K.-H. Baek, "Relationship between leptin receptor and polycystic ovary syndrome," Gene, vol. 527, no. 1, pp. 71-74, 2013.

[128] D. V. Lagaly, P. Y. Aad, J. A. Grado-Ahuir, L. B. Hulsey, and L. J. Spicer, "Role of adiponectin in regulating ovarian theca and granulosa cell function," Molecular and Cellular Endocrinology, vol. 284, no. 1-2, pp. 38-45, 2008.

[129] K. A. Toulis, D. G. Goulis, D. Farmakiotis et al., "Adiponectin levels in women with polycystic ovary syndrome: a systematic review and a meta-analysis," Human Reproduction Update, vol. 15, no. 3, pp. 297-307, 2009.

[130] S. K. Agarwal, K. Vogel, S. R. Weitsman, and D. A. Magoffin, "Leptin antagonizes the insulin-like growth factor-I augmentation of steroidogenesis in granulosa and theca cells of the human ovary," Journal of Clinical Endocrinology and Metabolism, vol. 84, no. 3, pp. 1072-1076, 1999.

[131] P. F. Svendsen, M. Christiansen, P. L. Hedley, L. Nilas, S. B. Pedersen, and S. Madsbad, "Adipose expression of adipocytokines in women with polycystic ovary syndrome," Fertility and Sterility, vol. 98, no. 1, pp. 235-241, 2012.

[132] E. P. Wickham III, T. Tao, J. E. Nestler, and E. A. McGee, "Activation of the LH receptor up regulates the type 2 adiponectin receptor in human granulosa cells," Journal of Assisted Reproduction and Genetics, vol. 30, no. 7, pp. 963-968, 2013. 


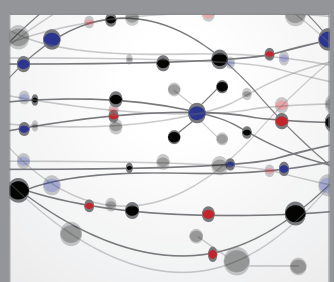

The Scientific World Journal
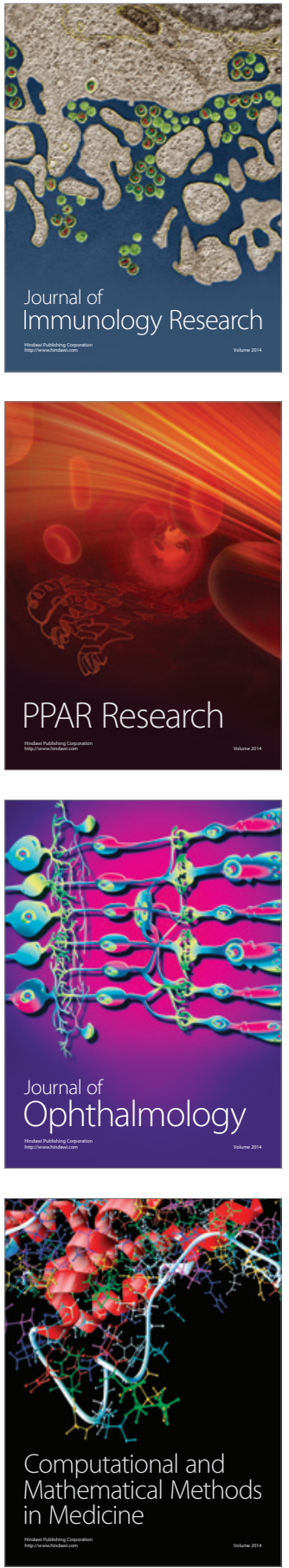

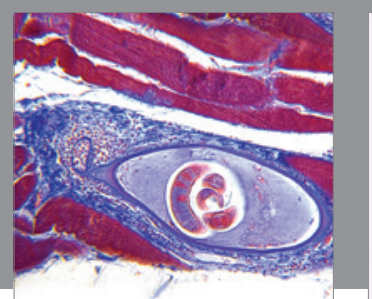

Gastroenterology Research and Practice

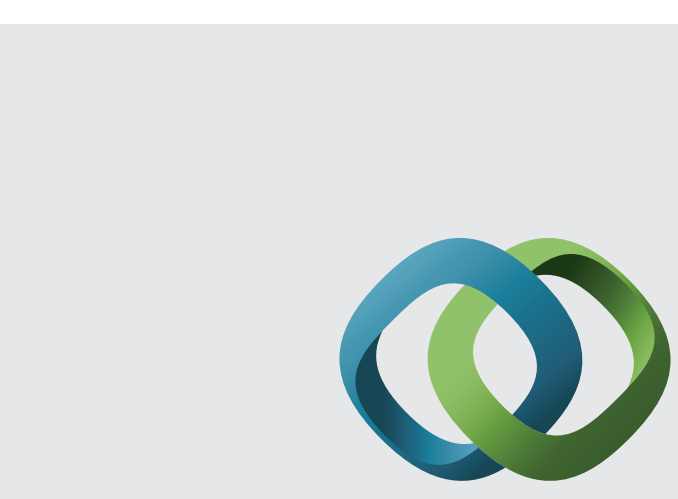

\section{Hindawi}

Submit your manuscripts at

http://www.hindawi.com
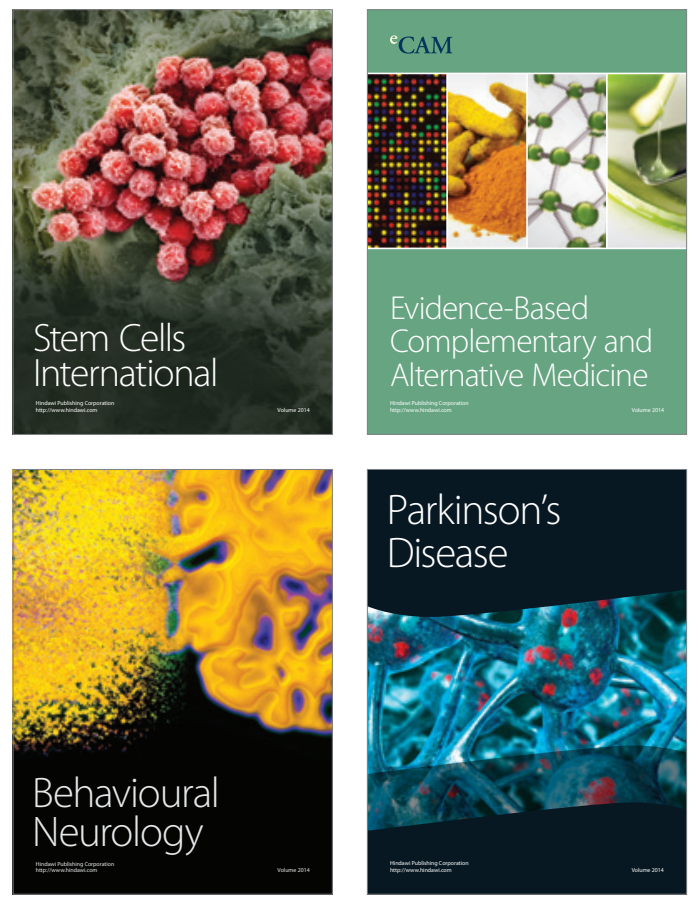
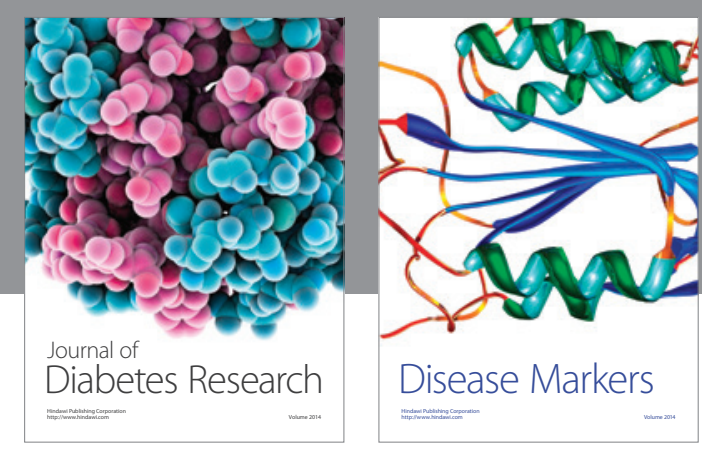

Disease Markers
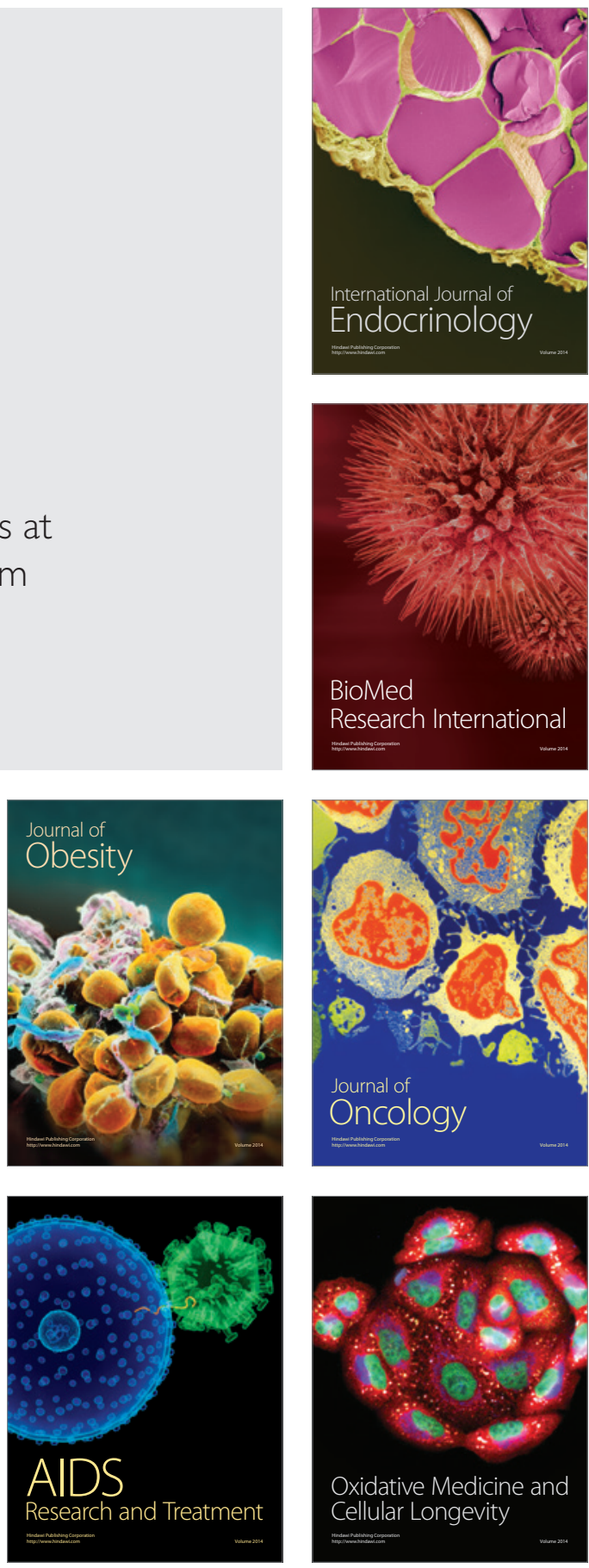